\title{
Tool wear of uncoated carbide and PVD TiAIN coated carbide tools in end milling of AlSi/AIN metal matrix composite
}

\author{
S. H. Tomadi ${ }^{1}{ }^{*}$, J. A. Ghani ${ }^{2}$, H. Mas Ayu ${ }^{1}$, R. Daud ${ }^{1}$ \\ ${ }^{1}$ Faculty of Mechanical Engineering, Universiti Malaysia Pahang, Pahang, Malaysia \\ ${ }^{2}$ Faculty of Engineering and Built Environment, Department of Mechanical and Material Engineering, Universiti Kebangsaan \\ Malaysia, Bangi, Selangor, Malaysia
}

\section{A R T I C L E IN F O}

\section{Article history:}

Received 5 February 2017

Received in revised form

31 July 2017

Accepted 31 July 2017

Keywords:

Tool wear

AlSi/AlN MMC

End milling

Uncoated carbide

PVD TiAlN coated carbide

\begin{abstract}
A B S T R A C T
In this paper, the tool life and wear mechanism of uncoated carbide tool and PVD TiAlN coated carbide are analyzed when end milling of AlSi/AlN metal matrix composite (MMC) with cutting speeds in the range of $240 \mathrm{~m} / \mathrm{min}$ to $400 \mathrm{~m} / \mathrm{min}$. The results show that at all cutting speed conditions, wear mechanism is dominated by abrasion and adhesion due to the hard particles that adhere temporarily or permanently on the flank face of cutting tool and scratch the surface. As a result, the formation of grooves is observed, and particles of cemented tungsten carbide are pulled-out due to the collision between AlN and carbide at the higher cutting speed of $400 \mathrm{~m} / \mathrm{min}$. This high cutting speed had caused cracking on the cutting edge. BUE was formed and deposited on the rake face. In this study, it was found that cutting speed is the most significant factor which contributed $76 \%$ to the cutting tool life compared to the depth of cut $(13.86 \%)$ and feed rate $(5.63 \%)$. This is believed to be due to the reaction between cutting tool and AISi/AIN MMC that will cause the increasing of cutting temperature and resulting in the tool wear of cutting tool.
\end{abstract}

(C) 2017 The Authors. Published by IASE. This is an open access article under the CC BY-NC-ND license (http://creativecommons.org/licenses/by-nc-nd/4.0/).

\section{Introduction}

Metal matrix composite (MMC) is a combination type of lightweight material between matrix and reinforcement materials which has high strength, high hardness, good wear resistance, and excellent strength to weight ratio (Muthukrishnan et al., 2008). It has been a potential material used in various engineering applications such as automotive, aerospace and recreational applications (Kremer and Mansori, 2011). The selection of particle size in MMC reinforcements is one of the appropriate processes due to its mechanical properties. However the larger size of particle reinforcements causes the poor machinability of MMC and a shorter cutting tool life. This is due to the higher hardness of reinforcement material (Kainer, 2006). During machining, the larger particle reinforcements will cause rapid wear of a cutting tool (Kannan et al., 2006). Several research studies been made to study the effect of particle size reinforcements to cutting

\footnotetext{
* Corresponding Author.

Email Address: sharyani@ump.edu.my (S. H. Tomadi) https://doi.org/10.21833/ijaas.2017.09.021

2313-626X/C) 2017 The Authors. Published by IASE.

This is an open access article under the CC BY-NC-ND license

(http://creativecommons.org/licenses/by-nc-nd/4.0/)
}

tool wear and they show that larger sizes of particle reinforcements have a major impact on cutting tool life as well as the cutting speed (Ciftci et al., 2004).

Abrasion and adhesion wear are the main wear mechanisms in machining of MMC. They occur due to the matrix material smeared on the tool face where the larger sizes of hard particle reinforcements scratch and form grooves on the tool face.

Kök (2010) carried out research to evaluate the effect of reinforcements on the machining of MMC with single layer (K10) and triple layer (TP30) coated carbide tool inserts under drying cutting speed ranges from $100 \mathrm{~m} / \mathrm{min}$ to $210 \mathrm{~m} / \mathrm{min}$. He reinforced the MMC with larger size particles from 16 to $66 \mu \mathrm{m}$. He found that the tool life recorded between 0.5 and 5 minutes only. For K10 coated carbide, the coating was removed from the tools when machining the material due to the high pressure generated at the tool-workpiece interface, and the abrasion and adhesion wear occurred on the flank faces of the tool. A built-up edge (BUE) was formed and deposited on the rake face of the tool which provides benefits since it protects the tool rake face from further abrasion. However, the smooth flank wear and a small amount of adhering material on the flank face were observed and no such a BUE formed for TP30 coated carbide. 
Seeman et al. (2010) studied tool wear in the machining of particulate aluminium metal matrix composite and observed that flank wear (VBmax) was increased with the increase in cutting speed. At lower cutting speeds, tool wear occurred to a lesser extent, which was attributed to the formation of larger size unstable BUE due to high contact pressure and friction. Different abrasive wear grooves were seen on the flank face while turning $\mathrm{Al} / \mathrm{SiCp}$ metal matrix composite material at low cutting speed $(50 \mathrm{~m} / \mathrm{min})$. Meanwhile, when the cutting speed increased to $150 \mathrm{~m} / \mathrm{min}$, abrasion and adhesion wear on the flank face was seen, mainly due to the generation of high contact pressure and temperature between the workpiece and tool surface.

This paper focused on the tool wear of uncoated carbide tools and PVD TiAlN coated carbide when end milling of AlSi/AlN metal matrix composite (MMC) with smaller size of particle reinforcements averaging $1 \mu \mathrm{m}$ and cutting speeds in the range of $240 \mathrm{~m} / \mathrm{min}$ to $400 \mathrm{~m} / \mathrm{min}$. The influence of the smaller particle size reinforcements and various cutting speed on tool wear are discussed, and presented.

\section{Experiment set-up}

The workpiece material used in the experiment is an advanced material AlSi/AlN metal matrix composite (MMC). The different wt \% of AlN particles; 10, 15 and $20 \mathrm{wt} \%$ was used with the mean size of reinforcement particles being $<10 \mu \mathrm{m}$ and the purity $>98 \%$. The chemical composition of the AlSi alloy is shown in Table 1 . The major physical and mechanical properties of AlN are listed in Table 2. The AlSi/AlN MMC was fabricated by the stir casting method (Fig. 1) and passed through a double ageing process to increase mechanical properties such as strength and hardness.

Table 1: Chemical composition of AlSi alloy (Wt \%)

\begin{tabular}{ccccccc}
\hline $\mathrm{Si}$ & $\mathrm{Fe}$ & $\mathrm{Zn}$ & $\mathrm{Cu}$ & $\mathrm{Sn}$ & $\mathrm{Mg}$ & $\mathrm{Al}$ \\
\hline 11.10 & 0.42 & 0.02 & 0.02 & 0.016 & 0.011 & Balance \\
\hline
\end{tabular}

Table 2: Physical and mechanical properties of AlN

\begin{tabular}{cc}
\hline Purity $(\%)$ & 98 \\
\hline Molecular weight $(\mathrm{g})$ & 40.99 \\
Density (g/cm3) & 3.25 \\
Melting point $(\mathrm{oC})$ & 2200 \\
Average particle size $(\mu \mathrm{m})$ & 1 \\
colour & White grey \\
\hline
\end{tabular}

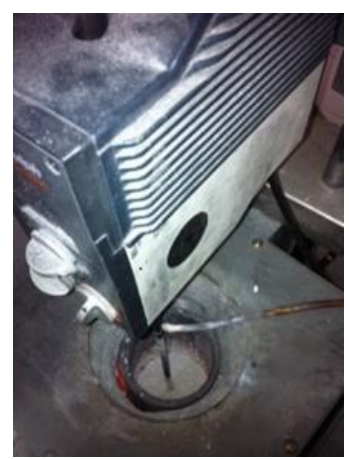

Fig. 1: Stir casting process in fabrication of AlSi/AIN MMC
The milling test was conducted using uncoated carbide inserts (Catalogue no: R390-11 T3 02E-KM H13A and R390-11 T3 02E-PM 1030) for PVD TiAlN coated carbide under dry cutting conditions. The cutting inserts were mounted on a tool body with a diameter of $20 \mathrm{~mm}$. The specifications of the cutting tool are shown in Table 3.

Table 3: Cutting tool specifications

\begin{tabular}{cc}
\hline Tool type & $\begin{array}{c}\text { Uncoated and PVD TiAlN coated } \\
\text { carbide }(2.2 \mu \mathrm{m} \text { coating } \\
\text { thickness) }\end{array}$ \\
& \\
& \\
Manufacturer & $0.2 \mathrm{~mm}$ \\
Rake & $6.8 \mathrm{~mm}$ \\
Nose radius & $0.7 \mathrm{~mm}$ \\
W1 & $11.0 \mathrm{~mm}$ \\
$\mathrm{BS}$ & $3.59 \mathrm{~mm}$ \\
LE & $90^{\circ}$ \\
$\mathrm{S}$ & $10 \% \mathrm{CO}$ \\
Lead angle & \\
Base Material & EH520, fine-grained carbide, WC- \\
\hline
\end{tabular}

The end milling process was used in this experimental study using a high precision CNC milling machine, DMC635V eco DMGECOLINE vertical milling machine with a maximum speed of 8000 RPM. The effects of the parameters on tool wear were studied by conducting a set of experiments, Taguchi method under dry cutting conditions. The cutting parameters are listed in Table 4. Cutting inserts were attached in the tool body with a diameter of $\varnothing 20 \mathrm{~mm}$.

Eighteen experiments were carried out to determine tool wear. The type of milling performed in this experimental investigation was "down milling." The radial depth of each pass was kept constant at $5 \mathrm{~mm}$. The wear progression on the cutting edge was measured using two-axis toolmaker's microscope with a digital micrometer for the $\mathrm{x}$-axis and $\mathrm{y}$-axis with $0.001 \mathrm{~mm}$ resolution. For these experiments, $0.3 \mathrm{~mm}$ flank wear (VB) was taken as the tool life criteria.

The variable pressure scanning electron microscope (VPSEM) model Leo-Zeiss 1450 and Genesis 4000 XMS energy-dispersive x-ray spectroscopy (EDAX) were used to capture the microscopic images of tool damage and analyze the element composition of the wear surface.

Table 4: Cutting parameters

\begin{tabular}{ccccc}
\hline Parameters & Facto & \multicolumn{3}{c}{ Level } \\
\hline Type of cutting tool & A & 1 & 2 & 3 \\
Cutting speed & B & 240 & 320 & 400 \\
Feed rate & C & 0.3 & 0.4 & 0.5 \\
Axial depth of cut & D & 0.3 & 0.4 & 0.5 \\
\% reinforcement & E & 10 & 15 & 20 \\
\hline
\end{tabular}




\section{Results and discussion}

\subsection{Evaluation of tool life}

The tool life of uncoated carbide and PVD TiAlN coated carbide inserts while machining AlSi/AlN Metal Matrix Composite are shown in Table 5 and Table 6. Both coated and uncoated carbide inserts have $0.3 \mathrm{~mm}$ maximum flank wear (VB). The two tables indicate that the tool life for coated and uncoated carbide increased tremendously when machining of AlSi/AlN MMC compared to the previous MMC machining done by other researchers. This is due to the smaller size particle reinforcements in the machined material. MMC with the larger size and high hardness of particle reinforcements caused higher pressure strength on the surrounding of particles due to the obstruction of plastic deformation, resulting in a fracture of particles. Besides, coarse particles may have more defects, which leads to rapid tool wear and worsens surface finish during machining as done by other researchers (Quan et al., 1999; Pramanik et al.,
2008). It is concluded that the usage of carbide cutting tools is sufficient in machining of AlSi/AlN MMC with a smaller size of particle range of 1 to 2 $\mu \mathrm{m}$.

However, the smaller size of particle reinforcements can cause these particles to coagulate among them in the matrix material. Breaking these clot particles could be done by mixing them with the appropriate method in the preparation of the workpiece, as well as pre-heating the reinforcement particles. With the addition of AlN in AlSi matrix material and thus form an advanced material of MMC, it will improve mechanical properties such as hardness and tensile strength. AlN particles are not diluted with matrix material due to the higher melting point of AlN compared to aluminium alloys (Manna and Bhattacharayya, 2003). Weak bonding between the AlN particles and matrix material is easily damaged due to the local flow of the matrix material and the pressure exerted by the tool. These particles are freely moved and have been trapped between the matrix material and the surface of the flank of the tool and cause abrasive wear.

Table 5: Tool life of uncoated carbide tool

\begin{tabular}{cccccc}
\hline \multirow{2}{*}{ No } & Cutting speed (m/min) & Feed rate (mm/ tooth) & DOC (mm) & \% of AlN volume fraction & Tool life (min) \\
\hline 1 & 240 & 0.3 & 0.3 & 10 & 70.7 \\
2 & 240 & 0.4 & 0.4 & 15 & 57.2 \\
3 & 240 & 0.5 & 0.5 & 20 & 48.33 \\
4 & 320 & 0.3 & 0.3 & 15 & 60 \\
5 & 320 & 0.4 & 0.4 & 20 & 49.83 \\
6 & 320 & 0.5 & 0.5 & 10 & 30.87 \\
7 & 400 & 0.3 & 0.4 & 10 & 27.25 \\
8 & 400 & 0.4 & 0.5 & 15 & 26.53 \\
9 & 400 & 0.5 & 0.3 & 20 & 28.1 \\
\hline
\end{tabular}

Table 6: Tool life of PVD TiAlN coated carbide tool

\begin{tabular}{cccccc}
\hline No & Cutting speed $(\mathrm{m} / \mathrm{min})$ & Feed rate $(\mathrm{mm} /$ tooth) & DOC $(\mathrm{mm})$ & \% of AlN volume fraction & Tool life $(\mathrm{min})$ \\
\hline 10 & 240 & 0.3 & 0.5 & 20 & 49.73 \\
11 & 240 & 0.4 & 0.3 & 10 & 62.5 \\
12 & 240 & 0.5 & 0.4 & 15 & 54.08 \\
13 & 320 & 0.3 & 0.4 & 20 & 47.1 \\
14 & 320 & 0.4 & 0.5 & 10 & 33.83 \\
15 & 320 & 0.5 & 0.3 & 15 & 44.33 \\
16 & 400 & 0.3 & 0.5 & 15 & 34.92 \\
17 & 400 & 0.4 & 0.3 & 20 & 23.35 \\
18 & 400 & 0.5 & 0.4 & 10 & \\
\hline
\end{tabular}

From Fig. 2, built up edge (BUE) was found at the nose of the cutting tool. However, the BUE formation on the uncoated carbide are much greater compared to PVD TiAlN coated carbide. Fig. 2a shows the BUE and BUL (Built up layer) was formed on the uncoated carbide tool. This phenomenon occurred due to the friction, high temperature and pressure on the particles of AlSi/AlN MMC adhering to the cutting tool materials during machining. The cyclic process of machining will cause more particles to join up with those already adhering and resulting in the formation of BUE. BUE also formed due to the high friction and temperature between the chip of AlSi matrix and the cutting tool, the chip metal welds itself to the cutting tool edge. The BUE formation acts as a protective cover on the nose area and will prolong the tool life of uncoated carbide tools in the machining of AlSi/AIN MMC. This phenomenon also happens during machining of other MMC (Karakaş et al., 2006; Muthukrishnan et al., 2007).

Fig. $2 \mathrm{~b}$ shows the coating material, TiAlN was abraded from the base material of WC-Co. This will cause a shorter tool life. Due to the similar geometry for both cutting tools, there might be a reaction between TiAlN coating which has a fragile characteristic and workpiece material of AlSi/AlN MMC. The thin TiAlN coating layer $(2.2 \mu \mathrm{m}) \mathrm{might}$ lead to the possibility of transition in the structure of the coating material, which is fragile, with the AlSi matrix material and resulting in abraded TiAlN from the base material.

Sahin et al. (2002) also believed that the coating layer (thin and fragile) on the tool would crack and become detached when machining MMC resulting in 
shorter tool life and wear on the tool would easily occur at cutting speeds of more than $200 \mathrm{~m} / \mathrm{min}$.

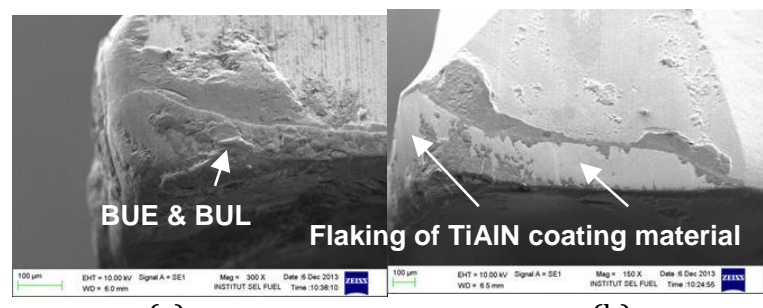

(a)

(b)

Fig. 2: Tool conditions (a) uncoated carbide and (b) PVD TiAlN coated carbide after end milling machining of AlSi/AlN MMC

\subsection{Effect of cutting parameters on the tool wear}

ANOVA analysis aimed to investigate the effect of each parameter on tool wear as shown in Table 7. In the analysis of cutting parameter effects via Taguchi method, the significant value $(\mathrm{P})$ of each parameter was set to be 0.05 . The $P$ value for cutting speed was calculated as 0.000 , feed rate 0.003 , DOC 0.000 , and $\%$ of AlN volume fraction 0.033 . However the P value of type of cutting tool was stated as not significant with a value of 0.26 . The smaller the $P$ value shows the most significant factor effects to the performance characteristics.

From Table 7, cutting speed was listed as the most significant factor affecting tool life. The contribution being 76.07 percent, followed by DOC; 13.86 percent, feed rate; 5.63 percent and percentage of AlN volume fraction; 2.36 percent. The findings obtained are similar to previous researchers. From Kök's (2010) analysis and Muthukrishnan et al.'s (2008), both found that tool life was dependent on cutting speed in machining MMC and was concluded as the most significant factor. Another researcher, Seeman et al. (2010) found that the deterioration of cutting tool life was detected at higher cutting speeds. DOC was stated as the second factor which affected tool life.

Table 7: ANOVA analysis for the cutting parameters effect on tool life

\begin{tabular}{cccccccc}
\hline Factor & Symbol & DF & SS & V & F & P & Cont (\%) \\
\hline Type of cutting tool & A & 1 & 0.503 & 0.5027 & 1.46 & 0.26 & 0.32 \\
Cutting speed & B & 2 & 118.9 & 59.463 & 173.22 & 0 & 76.07 \\
Feed rate & C & 2 & 8.802 & 4.401 & 12.82 & 0.003 & 5.63 \\
DOC & D & 2 & 21.66 & 10.831 & 31.55 & 0 & 13.86 \\
\% of AlN volume fraction & E & 2 & 3.691 & 1.8455 & 5.38 & 0.033 & 2.36 \\
Error & & 8 & 2.746 & 0.3433 & & & 1.76 \\
Total & & 17 & 156.3 & & & & 100 \\
\hline
\end{tabular}

Fig. 3 shows the interaction of cutting speed and DOC on tool life. The Figure shows that both cutting parameters affected cutting tool life. When higher speed and higher DOC were applied during machining ( $400 \mathrm{~m} / \mathrm{min}$ and $0.5 \mathrm{~mm})$, shorter tool life was obtained.

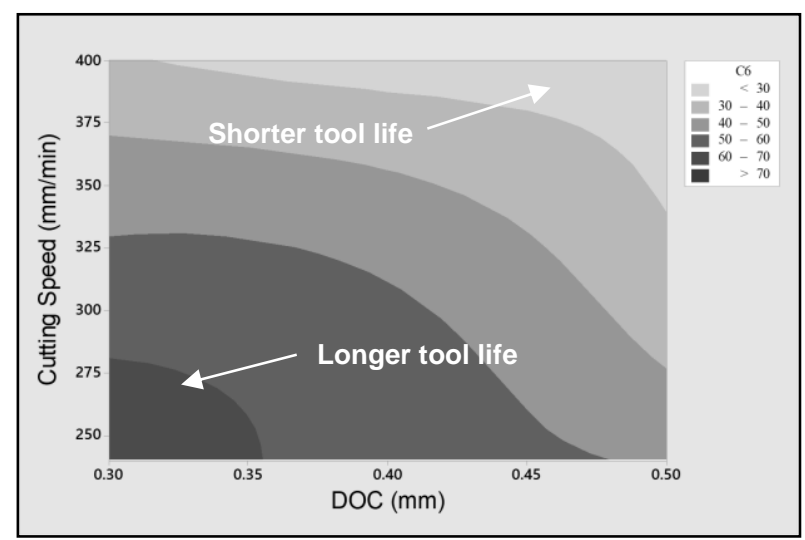

Fig. 3: Effects of cutting speed and DOC on tool life

\subsection{Wear mechanism of uncoated carbide tool}

Machining at a cutting speed of $240 \mathrm{~m} / \mathrm{min}$ resulted in the failure of the uncoated carbide cutting tool after 70.7 minutes as shown in Fig. 4. The cutting edge was smeared with BUE. The formation of unstable BUE can be seen at the nose area due to high contact pressure and friction. The formation of BUE was then deposited to the rake face, as shown in Fig. 5. From this, it is clearly observed that the failure is due to adhesion and abrasion. Abrasion and adhesion marks are evident primarily on the flank face. The adhering layer of workpiece material protected the tool's flank face against further abrasion (Seeman et al., 2010). On the other hand, if cutting speeds are lowered, temperature in the cutting zone will decrease. This will cause strain hardening of matrix material resulting in very difficult removal of adhered material. The wear mechanism at higher cutting speeds is similar to the lower cutting speeds; abrasion and adhesion wear. From the figure, the adhered material at the flank face is clearly seen.

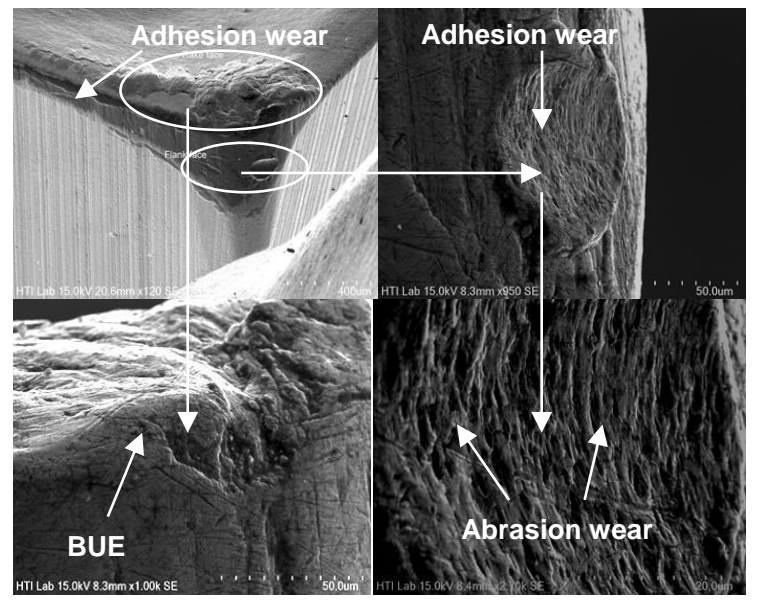

Fig. 4: Wear mechanism in uncoated Carbide at cutting speed $240 \mathrm{~m} / \mathrm{min}$, feed rate $0.3 \mathrm{~mm} /$ tooth, DOC $0.3 \mathrm{~mm}$ and $10 \%$ of AlN volume fraction 
Machining at a cutting speed of $400 \mathrm{~m} / \mathrm{min}$ resulted in the failure of the uncoated carbide cutting tool after 26.53 minutes. Smaller amounts of BUE were seen as the cutting speed applied in the machining was higher.

The formation of BUE was then deposited to the rake face. Higher cutting speeds cause higher temperatures that cause softening and reduce the adhered material on tools and resulting in the shorter tool life. The magnifications of flank wear are shown in Fig. 6.

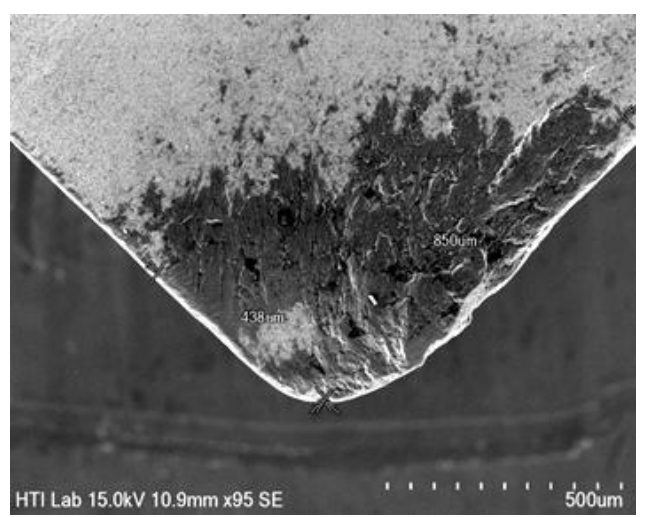

Fig. 5: Rake face of uncoated carbide at lower cutting speed of $240 \mathrm{~m} / \mathrm{min}$

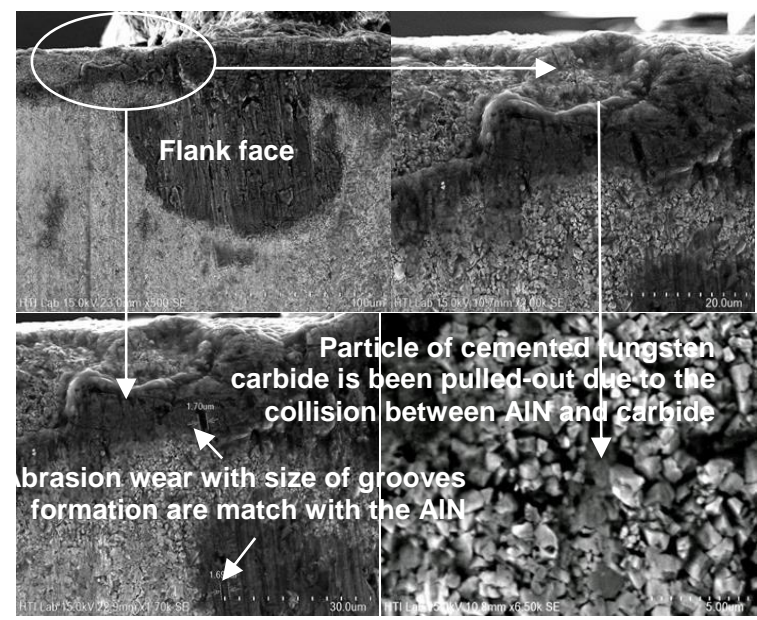

Fig. 6: Flank face of uncoated after machining at cutting speed $400 \mathrm{~m} / \mathrm{min}$, feed rate $0.4 \mathrm{~mm} /$ tooth, DOC $0.5 \mathrm{~mm}$ and $15 \%$ of AlN volume fraction

Abrasion wear is clearly seen with groove formation sizes which match with the AlN particle sizes of $1.7 \mu \mathrm{m}$ and $1.69 \mu \mathrm{m}$ in the range of $1-2 \mu \mathrm{m}$. This is due to particles that did not fracture during the cutting process. These observations are consistent with those of Pedersen and Ramulu (2006) and Quan et al. (1999).

Because of the smaller size of the AlN particles in this MMC, the particles were most likely either forced down into the workpiece or up into the chip without fracturing. The deterioration of the tool weakened the strength of the cobalt bond, which then caused the removal of the tungsten carbide particles from the cutting edge during machining. Particles of tungsten carbide were pulled-out due to the collision between AlN and carbide.

\subsection{Wear mechanism of PVD TiAlN coated carbide cutting tool}

Machining at a cutting speed of $240 \mathrm{~m} / \mathrm{min}$ resulted in the failure of the PVD TiAlN coated carbide cutting tool after 62.5 minutes. For a cutting speed of $400 \mathrm{~m} / \mathrm{min}$, it took only 23.35 minutes for the cutting tool to fail, as shown in Fig. 7. The minimized formation of BUE also can be seen clearly. Fig. 8 clearly shows that the cutting tool was fractured and cracked after the removal of the coating material. The increased temperature at high cutting speeds reduced the adhesion characteristics thereby minimizing the formation of BUE.

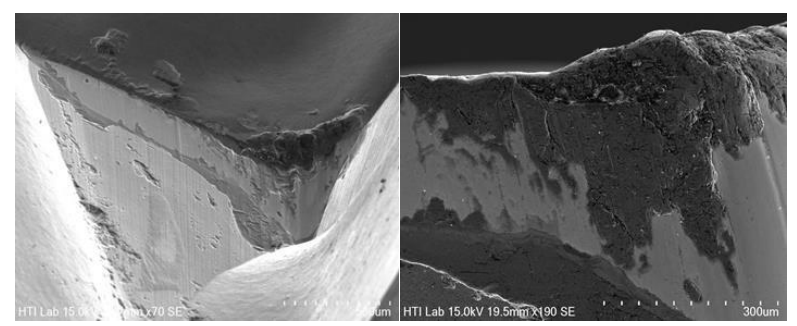

Fig. 7: Wear mechanism in PVD TiAlN coated carbide after machining at cutting speed $400 \mathrm{~m} / \mathrm{min}$, feed rate 0.5 $\mathrm{mm} /$ tooth, DOC $0.4 \mathrm{~mm}$ and $10 \%$ AlN

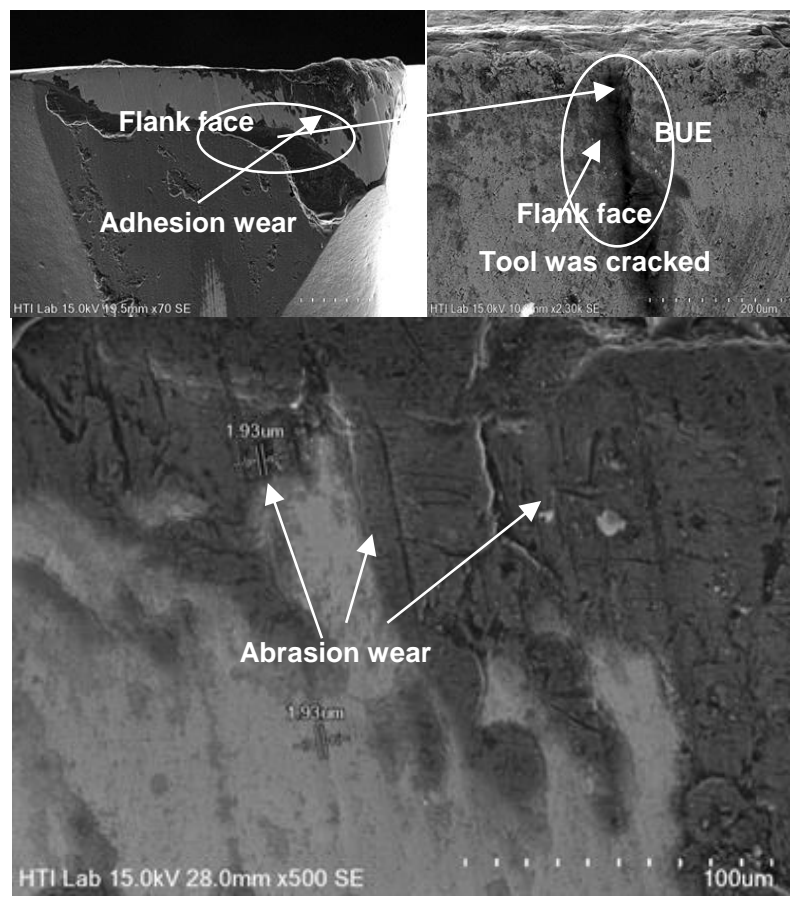

Fig. 8: Flank wear and cracked of PVD TiAlN coated carbide after machining at cutting speed $400 \mathrm{~m} / \mathrm{min}$, feed rate $0.5 \mathrm{~mm} /$ tooth, DOC $0.4 \mathrm{~mm}$ and $10 \% \mathrm{AlN}$

The primary wear mechanism of the tool was abrasion wear which caused by the reinforcement particles at the flank face of the tool followed by adhesion wear. At the end of the tool life, the coating material, TiAlN was abraded from the base material of WC-Co. It was caused by the abrasive nature of hard AlN particles reinforced in the workpiece material. The continuity of grooves that formed on the tool face can clearly be seen from the adhering layer to base material of WC-Co. The groove formation was measured and proved that the groove 
size of $1.93 \mu \mathrm{m}$ was matched to the particle size reinforcement.

\section{Conclusion}

Abrasion and adhesion wear are the primary wear mechanisms occurring during machining of AlSi/AlN MMC under dry cutting conditions. However it occurs after a longer time of machining. This is due to the smaller AlN particle size reinforcements in MMC. The tool life for uncoated carbide was recorded at a maximum 70.7 minutes and minimum 26.53 minutes. The BUE formation was observed and proved that it acts as a protective cover on the nose area and will prolong the tool life of uncoated carbide tool in the machining of AlSi/AlN MMC.

The tool life for PVD TiAlN coated carbide was recorded at a maximum 62.5 minutes and minimum 23.25 minutes. The wear of tool is due to the reaction between the thin TiAlN coating layer of 2.2 $\mu \mathrm{m}$ which has a fragile characteristic and workpiece material of AlSi/AIN MMC. It led to the possible of transition in the structure of the coating material with the AlSi matrix material and resulted in the abrasion of TiAlN from the base material. The tool was fractured and cracked due to the higher cutting speed applied.

Cutting speed is the most significant factor which contributes to the tool life of cutting tool. It also found that tool life decreased when the cutting speed increased from $240 \mathrm{~m} / \mathrm{min}$ to $400 \mathrm{~m} / \mathrm{min}$. When higher speed and higher DOC were applied during machining ( $400 \mathrm{~m} / \mathrm{min}$ and $0.5 \mathrm{~mm}$ ), shorter tool life was obtained. When the cutting speed increases, the cutting temperature will increase and will result in the deterioration of cutting tool performance.

\section{References}

Ciftci I, Turker M, and Seker U (2004). Evaluation of tool wear when machining $\mathrm{SiC}$ p-reinforced $\mathrm{Al}-2014$ alloy matrix composites. Materials and Design, 25(3): 251-255.

Kainer KU (2006). Metal matrix composites: custom-made materials for automotive and aerospace engineering. John Wiley and Sons, Hoboken, USA.
Kannan S, Kishawy HA, Deiab IM, and Surappa MK (2006). On the role of reinforcements on tool performance during cutting of metal matrix composites. Journal of Manufacturing Processes, 8(2): 67-75.

Karakaş MS, Acır A, Übeyli M, and Ögel B (2006). Effect of cutting speed on tool performance in milling of $\mathrm{B} 4 \mathrm{C} \mathrm{p}$ reinforced aluminum metal matrix composites. Journal of Materials Processing Technology, 178(1): 241-246.

Kök M (2010). Tool life modeling for evaluating the effects of cutting speed and reinforcements on the machining of particle reinforced metal matrix composites. International Journal of Minerals, Metallurgy, and Materials, 17(3): 353-362.

Kremer AEl and Mansori M (2011). Tool wear as-modified by particle generation in dry machining. Wear, 271(9): 24482453.

Manna A and Bhattacharayya B (2003). A study on machinability of Al/SiC-MMC. Journal of Materials Processing Technology, 140(1): 711-716.

Muthukrishnan N, Murugan M, and Prahlada RK (2007). Machinability issues in turning of Al-SiC (10p) metal matrix composites. The International Journal of Advanced Manufacturing Technology, 39(3-4): 211-218.

Muthukrishnan N, Murugan M, and Rao K (2008). An investigation on the machinability of Al-SiC metal matrix composites using pcd inserts. The International Journal of Advanced Manufacturing Technology, 38(5-6): 447-454.

Pedersen W and Ramulu M (2006). Facing SiCp/Mg metal matrix composites with carbide tools. Journal of Materials Processing Technology, 172(3): 417-423.

Pramanik A, Arsecularatne JA, and Zhang LC (2008). Machining of particulate-reinforced metal matrix composites. Davim JP (Ed.), Machining: fundamentals and recent advances: 127-166. Springer Science \& Business Media, Berlin, Germany.

Quan YM, Zhou ZH, and Ye BY (1999). Cutting process and chip appearance of aluminum matrix composites reinforced by $\mathrm{SiC}$ particle. Journal of Materials Processing Technology, 91(1): 231-235.

Sahin Y, Kok M, and Celik H (2002). Tool wear and surface roughness of $\mathrm{Al}_{2} \mathrm{O}_{3}$ particle-reinforced aluminium alloy composites. Journal of Materials Processing Technology, 128(1): 280-291.

Seeman M, Ganesan G, Karthikeyan R, and Velayudham A (2010). Study on tool wear and surface roughness in machining of particulate aluminum metal matrix composite-response surface methodology approach. The International Journal of Advanced Manufacturing Technology, 48(5-8):613-624. 